\title{
4D Electrical Resistivity Tomography monitoring of soil moisture dynamics in an operational railway embankment
}

\author{
Chambers, JE*, Gunn, DA, Wilkinson, PB, Meldrum, PI, Haslam, E, Holyoake, S, Kirkham, M, \\ Kuras, O, Merritt, A, Wragg, J \\ British Geological Survey, Keyworth, Nottingham, NG12 5GG \\ * Corresponding author, email: jecha@bgs.ac.uk
}

KEYWORDS: earthworks, embankment, electrical resistivity tomography (ERT), monitoring, soil moisture

\section{ABSTRACT}

The internal moisture dynamics of an aged ( $>100$ years old) railway earthwork embankment, which is still in use, have been investigated using 2D and 3D resistivity monitoring. A methodology was employed that included automated 3D ERT data capture and telemetric transfer with on-site power generation, the correction of resistivity models for seasonal temperature changes, and the translation of subsurface resistivity distributions into moisture content based on petrophysical relationships developed for the embankment material. Visualisation of the data as 2D sections, 3D tomograms and time series plots for different zones of the embankment enabled the development of seasonal wetting fronts within the embankment to be monitored at a high spatial resolution, and the respective distributions of moisture in the flanks, crest and toes of the embankment to be assessed. Although the embankment considered here is at no immediate risk of failure, the approach developed for this study is equally applicable to other more high-risk earthworks and natural slopes. 


\section{INTRODUCTION}

The impacts of railway earthwork failure can be severe, including loss of serviceability (insurance claims), human casualties, and reconstruction costs. Many of these structures were built between 100 - 200 years ago as steam railway and canal systems were developed in many countries. They were constructed using tipping methods, as was standard in the $19^{\text {th }}$ century, but this has left a legacy of ageing, highly fissured, weak and heterogeneous earth structures, which are still intensively used but prone to failure under aggressive climatic stresses (e.g. Perry et al., 2003; Donohue et al., 2011). Instability in clay rich natural and artificial slopes (i.e. embankments and cuttings) typically occurs due to progressive geotechnical property change and a reduction in strength in response to moisture content and pore pressure changes (Bromhead 1986; Clarke and Smethurst, 2010; Manning et al., 2008), driven by seasonal wetting and drying.

The condition of these earth structures and their resilience to climatic stresses can be difficult to determine due to the complexity of fill materials and the limitations of current approaches to characterisation and monitoring. For example, observation of change in surface morphology from walk over surveys or remote sensing (Miller et al., 2012) generally indicates late-stage failure, while point sensors provide insufficient spatial sampling density to adequately characterise, and therefore monitor processes and property changes leading to failure in highly heterogeneous subsurface conditions.

Geophysical ground imaging techniques offer the potential to complement existing approaches by spatially characterising and monitoring the internal conditions of earthworks to provide high resolution information of subsurface property changes, and hence precursors to slope failure. Resistivity imaging, or electrical resistivity tomography (ERT), holds particular promise due to its sensitivity to both lithological variations (e.g. Shevnin et al., 2007) and changes in soil moisture, which can be imaged by applying appropriate petrophysical relationships linking resistivity and saturation (e.g. Cassiani et al., 2009; Brunet et al., 2010). Two-dimensional ERT is now a well-established technique for investigating natural slopes with numerous recent examples of the use of the technique for structural characterisation and hydrogeological investigations (e.g. Jongmans and Garambois, 2007). Three-dimensional resistivity imaging, although less commonly applied, has also been used to investigate the internal structure and hydrogeological regimes associated with landslides in natural slopes (Lebourg et al., 2005; Heincke et al., 2010; Chambers et al., 2011; Di Maio and Piegari, 2011, 2012; Udphuay et al., 2011). The most common application of ERT for engineered slopes is embankment dam characterisation (Cho and Yeom, 2007; Kim et al., 2007; Husband et al., 2009; Minsley et al., 2011; Bedrosian et al., 2012; Oh, 2012) and monitoring (Sjodahl et al., 2008, 2009, 2010). 
Relatively few examples exist for transportation earthworks. Fortier et al. (2011) applied 2D ERT alongside other geophysical and geotechnical approaches to investigate a road embankment impacted by permafrost degradation; the ERT results were used to spatially characterise the structure and composition of the embankment. Jackson et al. (2002) used 2D resistivity imaging to monitor changing moisture distribution within a road embankment after pavement construction, which revealed a build up of moisture in the toe of the embankment prior to a slope failure event. A combined geophysical investigation, including 2D ERT, was undertaken by Donohue et al. (2011) of a railway embankment with a history of instability. Their investigations revealed soft clay and steeply sloping bedrock underlying the embankment, which were identified as a cause of instability. Chambers et al. (2008) applied 2D ERT to characterise and monitor the railway embankment considered in this study. Changes in the fill regime identified using ERT were closely associated with zones of poor track geometry, which was attributed to differential settlement at the interface between material types. Monitoring of the site revealed complex resistivity changes, which were attributed to the development of seasonal wetting fronts.

Alongside the increased use of ERT for slope investigations, purpose built ERT monitoring instrumentation has rapidly developed and now incorporates telemetric control and automatic data transfer, scheduling, and processing (LaBreque et al., 2004; Ogilvy et al., 2009). This type of instrumentation is now beginning to be applied to slope monitoring problems (Niesner, 2010; Supper et al., 2008; Wilkinson et al., 2010a; Sjödahl et al., 2009, 2010), although to the best of our knowledge this approach has not yet been applied to transportation earthworks.

In this study we use a combination of 2D and 3D ERT, and manual repeat and fully automated data capture to investigate the seasonal moisture dynamics of a section of railway embankment near Nottingham, UK. The embankment is representative of end tipped railway embankments constructed during the Ninetieth and early Twentieth Centuries, and is still used by an operational railway. The specific objectives of the study were: (1) to assess the efficacy of automated time-lapse electrical resistivity tomography (ALERT) instrumentation and data management and processing systems (incorporating ERT model temperature correction, and resistivity to moisture content property translation) to monitor the internal condition of a geotechnical railway asset; (2) to assess the magnitude and spatial distribution of seasonal ground moisture within the embankment. 


\section{SITE DESCRIPTION}

The study site is located on a section of the Great Central Railway embankment between Nottingham and Loughborough (Figs. 1 and 2), which is currently used by freight and heritage traffic. The embankment runs approximately north-south, and is located on a natural slope dipping a few degrees towards the west (Fig. 3). In the area of the study site the embankment is approximately $5.5 \mathrm{~m}$ high and $30 \mathrm{~m}$ wide, and has flanks heavily vegetated with deciduous trees, with oak dominating to the east and ash to the west.

The embankment was constructed in the 1890s using end tipping wagons (Bidder, 1990). Compaction was achieved by the subsequent movement of shunting locomotives and tipping wagons, resulting in significantly less compaction than is achieved using current construction practices. Materials for the embankment were excavated from cuttings to the south and north, and local sand and gravel pits. Intrusive investigations, comprising boreholes and static cone penetration tests (sCPT) (Figs. 2 and 3), have revealed that the study site is located on material taken from the southern cutting, which is dominated by Westbury Mudstone Formation lithoclasts, with sporadic cobbles of Blue Anchor Formation siltstone (Gunn et al., 2009). In the northern section of the study area the fill regime changes to sand and gravel, as indicated by a thin layer of sand and gravel to a depth of $1.75 \mathrm{~m}$ in borehole $\mathrm{F}$, which increases in thickness in borehole G (Gunn et al., 2008; Chambers et al., 2008). The embankment rests on mudstones of the Branscombe Formation.

\section{METHODOLOGY}

\section{ERT Monitoring}

A permanent ERT monitoring array has been installed within a $22 \mathrm{~m}$ section of the embankment, comprising twelve lines running perpendicular to the rails spaced at $2 \mathrm{~m}$ intervals. Each line has 32 electrodes spaced at $1 \mathrm{~m}$ intervals, running from the toe of the eastern flank to the toe of the western flank. Initial 2D ERT measurements, which commenced in July 2006, were made on one of the electrode lines using a Super Sting R8/IP resistivity instrument during repeated visits to the site. During the summer of 2010, an Automated TimeLapse Electrical Resistivity Tomography (ALERT) system was installed at the site along with the other eleven electrode lines to form the 3D imaging array. This enabled automated remote monitoring of the embankment, thereby eliminating the need for repeat monitoring visits to the site and significantly improving the temporal resolution (i.e. a measurement frequency of days/weeks compared to months). The ALERT system (Ogilvy et al., 2009; Wilkinson et al., $2010 a, b)$ provides near real-time in-situ monitoring of subsurface resistivity, using telemetry to 
130 communicate with a database management system, which controls the storage, inversion and

131 delivery of the data and resulting tomographic images. Once installed no manual intervention

132 is required; data is transmitted automatically to a pre-programmed schedule and survey 133 parameters, both of which may be modified remotely as conditions change. In this case telemetric data transmission, including measurement scheduling and data download, was via GPRS. The system was powered by a bank of $12 \mathrm{~V}$ batteries, which were recharged using solar panels and a direct-methanol fuel cell. The 2D imaging line ( $y=12 \mathrm{~m}, x=0$ to $31 \mathrm{~m})$ is located within the 3D imaging area ( $y=0$ to $22 \mathrm{~m}, x=0$ to $31 \mathrm{~m}$ ). The $y$-axis is parallel to the rails. The 2D ERT monitoring period extended from July 2006 to August 2010, although, in this study we consider monitoring events between October 2009 and July 2010, all of which are compared to the July 2006 baseline. The 3D ERT monitoring period was from September 2010 to February 2012.

All resistivity data were collected line-by-line using the dipole-dipole array configuration, with dipole sizes $(a)$ of $1,2,3$ and $4 \mathrm{~m}$, and unit dipole separations $(n)$ of $a$ to $8 a$. The dipole-dipole command sequences comprised full sets of both normal and reciprocal configurations; comparison of forward and reciprocal measurements provided a robust means of assessing data quality and determining reliable and quantitative data editing criteria.

The 2D and 3D ERT data were inverted using a regularized least-squares optimization algorithm (Loke and Barker, 1995; 1996), in which the forward problem was solved using the finite difference method. Sequential time-lapse inversion of the 2D ERT data was carried out using the approach described by Chambers et al. (2010), whereas the 3D ERT time series data were inverted independently. Good convergence between the observed and model data was achieved for both the 2D and the 3D models, as indicated by average RMS errors of $3.0 \%$ (standard deviation $0.6 \%$ ) and $5.8 \%$ (standard deviation $1.1 \%$ ) respectively.

$\underline{\text { Temperature Modelling and Resistivity Model Corrections }}$

156 A multi-level thermistor array and logger (Fig. 3) was used at the test site to determine 157 seasonal temperature changes in the subsurface (Fig. 4). These data have been used to correct 158 the time-lapse ERT images for temperature effects using a methodology similar to that 159 described by Brunet et al. (2010). Seasonal temperature changes in the subsurface can be 160 described by the following equation, 
162 where $T(z, t)$ is the temperature at day $t$ and depth $z, T_{\text {mean }}$ (air) is the mean yearly air

163 temperature, $A$ is the yearly amplitude of the air temperature variation, $d$ is the characteristic 164 penetration depth of the temperature variations, $\varphi$ is the phase offset, $(\phi-z / d)$ is the phase $165 \mathrm{lag}$, and $\omega$ is the angular frequency $(2 \pi / 365)$. We fitted the temperature data (Fig. 4) to 166 Equation 1 using the FindMinimum[] function in the Mathematica computational algebra 167 package. This is a Quasi-Newton method, which uses the Broyden-Fletcher-Goldfarb-Shanno 168 algorithm to update the approximated Hessian matrix (Press et al. 1992). The modelled 169 seasonal temperature variations with depth were used to correct the 2D and 3D ERT models, 170 with the assumption that resistivity decreases by $2 \%$ per ${ }^{\circ} \mathrm{C}$ increase in temperature (Hayley et 171 al., 2007). Resistivities for all ERT models were normalised to the mean air temperature $172\left(11.1^{\circ} \mathrm{C}\right)$. The good fit between the modelled and observed temperatures for all sensor depths, 173 including the lowest sensor located in the bedrock, indicates that the thermal diffusivity of the embankment and bedrock materials are similar.

177 Laboratory measurements were carried out to establish the relationship between resistivity 178 and gravimetric moisture content in the material used to construct the embankment within 179 the area of the study site. Core samples were gathered via drilling sorties in September 2005 and July 2006. The core was sub-sampled into $200 \mathrm{~mm}$ sections, which were used to determine a range of estimated values of porosity, density and moisture content for the fill material. Samples were gently crushed to remove particles greater than $8 \mathrm{~mm}$ and re-saturated using distilled, deionised water to moisture contents between the shrinkage limit and liquid limit - in practice this ranges from $5 \%$ to $55 \% \mathrm{w} / \mathrm{w}$. The re-saturated materials were compacted into $100 \mathrm{~mm}$ diameter by $100 \mathrm{~mm}$ long core liners and sealed with plastic end caps; similar densities were achieved to those observed in undisturbed core. Sample moisture contents were verified on surplus material during preparation, and the sample masses were measured throughout testing to monitor moisture loss, which was less than $0.1 \%$. Multiple samples of reworked Westbury Formation Mudstone taken from different locations within the study area were used to represent the effects of the heterogeneity in the embankment (e.g. mineralogical and geotechnical property variations). Resistivity measurements were made using a non-contact inductive logging tool (Jackson et al., 2006). Prior to measurement, all samples were conditioned for at least 24 hours at a constant temperature in a temperature controlled cabinet. The electrical conductivity logging equipment was also conditioned at the same temperature, as were three additional fluid 
204

calibration samples of the same dimensions and of known resistivities 20, 200 and 2000 Ohm.m. At each selected measurement temperature, the internal temperature of a further water filled sample was used as a proxy to monitor any change in temperature within the test samples during the measurement phases. The temperature of the measuring head of the logger was also monitored to gauge the effect upon the test results.

To translate the resistivity to gravimetric moisture content, the resistivity data were fitted to a modified Waxman-Smits equation. The original Waxman-Smits (1968) model is defined in terms of saturation:

$\rho=\frac{F}{S^{n}}\left(\frac{1}{\rho_{\mathrm{w}}}+\frac{B Q_{\mathrm{v}}}{S}\right)^{-1}$.

Here, $\rho$ is the formation resistivity, $S$ is the saturation, $n$ is the saturation exponent, $F$ is the formation factor, $\rho_{\mathrm{w}}$ the pore water resistivity, $Q_{\mathrm{v}}$ is the cation concentration per unit pore volume, and $B$ is the average mobility of the ions. Converting moisture content to saturation for use with Equation 2 involves the porosity, which changes with moisture content in materials with significant clay content due to shrink-swell. In the modified form of the model (Equation 3), the porosity dependence appears as a multiplicative factor that only affects the formation factor, which is one of the parameters used to fit the resistivity - moisture content curve. Hence the form of the interpolating curve remains the same, whatever the assumed porosity. The modified model is

$$
\rho=F\left(\frac{\varphi P_{\mathrm{w}}}{(1-\varphi) P_{\mathrm{g}} G}\right)^{n}\left(\frac{1}{\rho_{\mathrm{w}}}+B\left(\frac{c P_{\mathrm{w}}}{100 G}\right)\right)^{-1}
$$

where $G$ is the gravimetric moisture content. We used an average measured porosity $\varphi=0.413$ and grain density $P_{\mathrm{g}}=2.65 \mathrm{~g} \mathrm{~cm}^{-3}$. The other known parameters were $\rho_{\mathrm{w}}=15 \Omega \mathrm{m}$, $P_{\mathrm{w}}=1.00 \mathrm{~g} \mathrm{~cm}^{-3}, c=21.93 \mathrm{meq} / 100 \mathrm{~g}$, and $B=1.98\left(\mathrm{Sm}^{-1}\right) \mathrm{cm}^{3} \mathrm{meq}^{-1}$. The best-fit model using these parameters was achieved with $n=1.60$ and $F=28.4$, giving an rms misfit error of $35 \%$ and a correlation coefficient of 0.89 (Fig. 5). The asymptotic standard errors in the best fit parameters are \pm 0.09 and \pm 3.5 respectively.

The resistivity-moisture relationship has been used to generate images of soil moisture from the temperature correct ERT models. The uncertainty associated with the resulting images of moisture content is a function of the accuracy of the temperature and moisture contentresistivity models, the resolution of the inverted resistivity images, and the heterogeneity of the embankment materials (some of which has been captured through the use of multiple Westbury Mudstone samples to develop the resistivity moisture content relationship). 
Air temperature and rainfall were logged using a Davis Vantage Pro2 weather station located adjacent to the railway line, less than $1 \mathrm{~km}$ to the northeast of the study site. Effective rainfall was determined from measured rainfall by estimating evapotranspiration using the Blaney and Criddle (1962) procedure (Fig. 6). This method is a temperature-based approach to estimating evapotranspiration, which compares favourably to other similar approaches (e.g. Xu and Singh, 2001). The Blaney-Criddle equation is given here as:

where, $E T$ is weekly evapotranspiration in $\mathrm{mm}, k$ is the consumptive use coefficient, which is related to vegetation type, $p$ is the percentage of weekly total daytime hours, and $T_{a}$ is the weekly mean air temperature in ${ }^{\circ} \mathrm{C}$. For this study a $k$ value of 0.65 was applied, which is appropriate for a vegetation cover of deciduous trees (Ponce, 1989).

2D Time-Lapse Imaging

Weather data for the 2D monitoring period (Fig. 6a) indicates that air temperature broadly correlates with that of ground temperature (Fig. 4), but shows far greater short-term variability. Rainfall is relatively consistent throughout the year, without any significant periods of very low or very high rainfall. However, the effective rainfall follows a strong seasonal cycle due to the influence of evapotranspiration (e.g. Ponce, 1989), with a negative trend during summer/autumn of 2009 and 2010 (i.e. evapotranspirative moisture loss exceeding actual rainfall), and positive during the intervening winter period (i.e. the volume of moisture entering the subsurface from rainfall exceeding that lost by evapotranspiration).

Resistivity

Temperature corrected resistivity and resistivity ratio images are shown in Fig. 7, and display significant spatial and temporal variability. The spatial heterogeneity is consistent with the findings of intrusive sampling at the site. In particular, a layered structure in the core of the embankment, and a temporally and spatially varying surface layer ( $2 \mathrm{~m}$ deep) across the flanks and crest are apparent in the models. The internal layered structure is likely to be a 
259 form of borehole (Fig. 3) and friction ratio logs (Gunn et al., 2009) indicate a 2 m layer of

260 granular material at the surface overlying more clayey fill, which is likely to account for the

261 more resistive material on the crest. Both of these zones are composed of Westbury

262 Formation mudstones, but the more granular structure of the overlying material results in a

263 more free draining material with lower moisture contents. Lower resistivities at the base of the

264 embankment may be related to elevated moisture contents resulting from water draining

265 down slope from the east and seepage from the embankment toe to the west.

266 No effects related to the metal rails are observed in the model. This is consistent with the 267 findings of Chambers et al. (2008) and Donohue et al. (2011), who attributed to absence of rail 268 related feature in resistivity models to the insulating effect of the coarse stone ballast that separates the rails and sleepers from the track bed.

270 Maximum seasonal ground temperature departures from the mean are approximately $10{ }^{\circ} \mathrm{C}$ 271 (Fig. 4, $0.5 \mathrm{~m}$ depth), which equates to a resistivity changes of $20 \%$. Although temperature has significantly influenced resistivity, the effect is relatively small compared to other drivers of resistivity change (i.e. moisture content), which have caused resistivity to change by more than a factor of 5 . Since the temperature tends to be low when the embankment is wet, and high when it is dry, the resistivity changes caused by seasonal temperature variations typically oppose those caused by the changes in moisture content. Therefore raw resistivity images would exhibit smaller seasonal changes than the temperature-corrected images. Similar conclusions can be drawn for the subsequent conversion to moisture content via Fig. 5 (the effect on the moisture content due to a temperature correction of $10^{\circ} \mathrm{C}$ is approximately $40 \%)$.

Most of the changes observed in the resistivity section are concentrated in the top 1 to $2 \mathrm{~m}$, and show a decrease in resistivity relative to the July 2006 baseline. The significant spatial variability of the observed resistivity changes again indicates the heterogeneity of the embankment. The section which shows maximum change relative to baseline is seen at t27 ( $30^{\text {th }}$ March 2010), and is related to moisture content.

Moisture content

287 The moisture content images are shown in terms of gravimetric moisture content (GMC), and GMC ratio. The bedrock region has been excluded from the images, as the property relationship (i.e. resistivity-moisture content, Fig. 5) has only been developed for the embankment material. Absolute GMCs are low, i.e. $<0.2$, for most of the embankment. The highest values are in the core, which does not appear to dry out during the monitoring period. 
$\mathrm{m}$. The increases in GMC relative to the baseline are entirely consistent with the development and regression of a seasonal wetting front, with maximum GMC occurring during periods of high effective rainfall. In the vicinity of the crest $(x=11-16 \mathrm{~m})$ very little GMC change is observed. This is probably due to the layer of free draining ballast in this area. The western flank generally displays higher GMCs than the east, which is probably due to it having a more northerly aspect, and being dominated by ash, which has a lower water demand and shorter growing season than the oak that dominate the eastern flank (Lawson and O'Callaghan, 1995). The relative influence of aspect and vegetation type cannot be determined from the images.

\section{D Time-Lapse Imaging}

\section{Seasonal temperature and rainfall}

The $3 \mathrm{D}$ monitoring period was generally drier than the $2 \mathrm{D}$, with negative effective rainfall dominating. A significant rainy period occurred in November/December 2010, with the next sustained period of positive effective rainfall occurring in the winter of 2011.

\section{Resistivity}

The same procedure for temperature correction and translation to GMC as described above was applied to the 3D data. During the 17 month monitoring period a total of 28 datasets were collected. Three examples are shown in Fig. 9 to illustrate results from the wettest and driest periods of the monitoring (February 2011, October 2011 and January 2012). Similarly complex patterns of resistivity to the 2D sections (Fig. 7) are observed, with particularly high resistivities observed just below the crest and shoulders of the embankment, which are probably related to the presence of relatively free draining material with low moisture contents.

\section{Moisture content}

The associated 3D GMC plots are shown in Fig. $9 \mathrm{~d}$, e, and $\mathrm{f}$ respectively. The bedrock and ballast layers have been removed from the 3D GMC visualisations. A general increase in moisture content is observed in the winter periods relative to the summer, although the pattern of GMC distribution is highly heterogeneous. The wettest zones occur just below the crest, associated with rapid drainage of rainfall through the ballast where it ponds on the mudstone, and towards the base of the flanks, where shade and tree canopy cover are greatest. Both these situations reduce the level of evaporative moisture loss.

Results from the entire monitoring period are shown as time series plots for different regions of the imaging volume (Fig. 10) to show the spatial and temporal variability of GMC in the imaging volume. The plots all reflect seasonal changes in moisture content following the trend 

of effective rainfall, with positive rainfall associated with the wetting of the embankment and negative with drying. However, with the higher temporal resolution, compared to that of the 2D imaging (Fig. 8), it is apparent that some of the time series data shows a lag between changes in positive and negative effective rainfall, and the accompanying change in subsurface moisture content. For example, significant reductions in moisture content during the spring of 2011 (e.g. Fig. 10b) only occurred after several weeks of negative effective rainfall - the acceleration of moisture content reduction during May is probably related to trees drawing more moisture as the growing seasons becomes established. Likewise a delay in moisture content increases seen in December 2011 (Fig. 10 a and b) as a period of positive effective rainfall occurs. This observed lag is a likely consequence of the time required for moisture to penetrate and migrate through the embankment. The influence of relatively short periods (days) of rainfall can be seen in the time series data - particularly during the transition from negative to positive effective rainfall during November 2011 (Fig. 10).

The time series data are shown for a range of spatial scales. In Fig. 10a, mean GMC are shown for the central region (including the crest), and the eastern and western flanks. The central region exhibits the highest GMC due to the consistently wet core of the embankment (as seen in the 2D imaging, Fig. 8). Differences between the eastern and western flanks are apparent, with the western flank having consistently slightly higher GMC. The reason for this difference, as discussed in the 2D imaging section, is the aspect and vegetation cover of the embankment.

Fig. 10b shows the mean GMCs for the toe regions of the eastern and western flanks. In assessing the stability of slopes the toe region is particularly significant as landslide events are very often related to failure processes that originate in the toe. In this region the western flank appears to be generally slightly wetter, which is probably again due to the aspect and vegetation cover, and also perhaps seepage from the toe region as the embankment drains to the west.

Time series for a smaller spatial scale are shown in Fig. 10c, which show the mean GMC of two clusters of 8 model voxels in the toe region of the western flank. These closely located volumes illustrate the high degree of spatial variability in GMC change, as they exhibit markedly different moisture content levels. The same seasonal trend is seen in both time series, but the red volume shows a much larger response to rainfall. At this spatial scale, root systems of individual trees, canopy cover, localised bioturbation (i.e. rabbit and fox holes), and lithological variations could contribute to the observed variability. 


\section{CONCLUSIONS}

Here we have demonstrated the use of time-lapse ERT for spatially monitoring the internal condition and moisture dynamics of a geotechnical railway asset. For the first time for this application, a methodology has been described that incorporates automated 3D ERT data capture and telemetric transfer using local on-site power generation, the correction of resistivity models for seasonal temperature changes, and the translation of subsurface resistivity distributions into moisture content. The benefits of automated data capture are clear, in that it permits monitoring at a greater temporal resolution that is achievable using manual repeat surveys. This is likely to be particularly important for slope failures related to rainfall events, which require monitoring over periods of hours to days, rather than weeks or months.

At this site the development of seasonal wetting fronts were observed, which correlated closely with effective rainfall. The spatially heterogeneity displayed in the subsurface was significant, and would have been very difficult to characterise and monitor using conventional point sensing approaches. Data visualisation has been provided as 2D sections, and as 3D tomograms and times series data for a range of spatial scales, to facilitate the interrogation of the monitoring datasets. The time series data were particularly effective for identifying seasonal moisture content trends and the moisture dynamics of different zones within the embankment structure, such as the flanks, crest, and toes regions.

Although moisture content is not the only parameter of interest (e.g. pore pressure is also a major driver of instability in some situations), it is nevertheless a crucial indicator of slope stability (e.g. Clarke and Smethurst, 2010). The development of this type of approach to asset monitoring provides the opportunity for upward trends in moisture content to be analysed as they approach critical thresholds (e.g. the liquid limit), thereby providing the possibility of early warning of potentially unstable embankment conditions. Although the asset condition observed at this site did not give serious cause for concern, the methodology demonstrated here is applicable to other more vulnerable engineered earth structures and natural slopes, and will be most appropriately applied to high-risk critical infrastructure.

\section{ACKNOWLEDGEMENTS}

This paper is published with the permission of the Executive Director of the British Geological Survey (NERC). We also gratefully acknowledge the Great Central Railway (Nottingham) Ltd. for allowing access on to the East Leake embankment, and David Anderson and Weather 
NSG_MSI_jec_vIR_5x.doc

Underground, Inc. for the provision of weather data. This research has been supported by the East Midlands Development Agency (emda) via the Single Programme fund.

\section{REFERENCES}

Bedrosian, P. A., Burton, B. L., Powers, M. H., Minsley, B. J., Phillips, J. D., Hunter, L. E., 2012.

Geophysical investigations of geology and structure at the Martis Creek Dam, Truckee, California. Journal of Applied Geophysics. 77, 7-20.

Bidder, F.W., 1900. The Great Central Railway Extension: Northern Division. ICE, Vol. CXLII, Session 1899-1900, Part IV, Paper 3227, pp 1-22.

Blaney, H.F., Criddle, W.D., 1962. Determining consumptive use and irrigation water requirements, U. S. Dept. Agr. Agricultural Research Service Tech Bull 1275.

Bromhead, E. N, 1986. The stability of slopes. Surrey University Press (Glasgow and New York, USA), ISBN 0412010615.

Brunet, P., Clement, R. \& Bouvier, C., 2010. Monitoring soil water content and deficit using Electrical Resistivity Tomography (ERT) - A case study in the Cevennes area, France. Journal of Hydrology, 380, 146-153.

Cassiani, G., Godio, A., Stocco, S., Villa, A., Deiana, R., Frattini, P., Rossi, M., 2009. Monitoring the hydrologic behaviour of a mountain slope via time-lapse electrical resistivity tomography. Near Surface Geophysics. 7, 475-486.

Chambers, J. E., Wilkinson, P. B., Kuras, O., Ford, J. R., Gunn, D. A., Meldrum, P. I., Pennington, C. V. L., Weller, A. L., Hobbs, P. R. N., Ogilvy, R. D., 2011. Three-dimensional geophysical anatomy of an active landslide in Lias Group mudrocks, Cleveland Basin, UK. Geomorphology. $125,472-484$.

Chambers, J. E., Gunn, D. A., Wilkinson, P. B., Ogilvy, R. D., Ghataora, G. S., Burrow, M. P. N., Smith, R. T., 2008. Non-invasive time-lapse imaging of moisture content changes in earth embankments using electrical resistivity tomography (ERT). Advances in Transportation Geotechnics. CRC Press-Taylor \& Francis Group, 475-480.

Chambers, J. E., Wilkinson, P. B., Wealthall, G. P., Loke, M. H., Dearden, R., Wilson, R., Allen, D. \& Ogilvy, R. D., 2010. Hydrogeophysical imaging of deposit heterogeneity and groundwater chemistry changes during DNAPL source zone bioremediation. Journal of Contaminant Hydrology, 118, 43-61.

Cho, I. K., Yeom, J. Y., 2007. Crossline resistivity tomography for the delineation of anomalous seepage pathways in an embankment dam. Geophysics. 72, G31-G38. 
Clarke, D. and Smethurst, J. (2010) Effects of climate change on cycles of wetting and drying in engineered clay slopes in England. Quarterly Journal of Engineering Geology and Hydrogeology, 43, (4), 473-486.

Di Maio, R., Piegari, E., 2011. Water storage mapping of pyroclastic covers through electrical resistivity measurements. Journal of Applied Geophysics. 75, 196-202.

Di Maio, R., Piegari, E., 2012. A study of the stability analysis of pyroclastic covers based on electrical resistivity measurements. Journal of Geophysics and Engineering. 9, 191-200.

Donohue, S., Gavin, K., Tolooiyan, A., 2011. Geophysical and geotechnical assessment of a railway embankment failure. Near Surface Geophysics. 9, 33-44.

Fortier, R., LeBlanc, A. M., Yu, W. B., 2011. Impacts of permafrost degradation on a road embankment at Umiujaq in Nunavik (Quebec), Canada. Canadian Geotechnical Journal. 48, 720-740.

Gunn, D. A., Reeves, H. J., Chambers, J. E., Ghataora, G. S., Burrow, M. P. N., Weston, P., Lovell, J. M., Nelder, L., Ward, D., Smith, R. T., 2008. New geophysical and geotechnical approaches to characterise under utilised earthworks. Advances in Transportation Geotechnics. CRC PressTaylor \& Francis Group, 299-305.

Gunn, D.A, Haslam, E., Kirkham, M, Chambers J.E, Lacinska, A, Milodowski A, Reeves, H, Ghataora, G, Burrow M, Weston, P., Thomas. A., Dixon, N., Sellers, R. \& Dijkstra, T., 2009. Moisture measurements in an end-tipped embankment: Application for studying long term stability and ageing. Proc. 10th Int. Conf. Railway Engineering, London.

Hayley, K., Bentley, L. R., Gharibi, M. \& Nightingale, M., 2007. Low temperature dependence of electrical resistivity: Implications for near surface geophysical monitoring. Geophysical Research Letters, 34, L18402.

Heincke, B., Gunther, T., Dalsegg, E., Ronning, J. S., Ganerod, G. V., Elvebakk, H., 2010. Combined three-dimensional electric and seismic tomography study on the Aknes rockslide in western Norway. Journal of Applied Geophysics. 70, 292-306.

Husband, C. R., Cassidy, N. J., Stimpson, I. G., 2009. The geophysical investigation of lake water seepage in the regulated environment of the Bosherston Lily Ponds, South Wales, UK. Part 2: historical, dam-related pathways. Near Surface Geophysics. 7, 517-528.

Jackson, P.D., Lovell, M.A., Roberts, J.A., Schultheiss, P.J., Gunn, D., Flint, R.C., Wood, A., Holmes, R. \& Frederichs, T., 2006. Rapid non-contacting resistivity logging of core. In. Rothwell, R.G. (Ed.), New techniques in sediment core analysis. Geol. Soc. Special Publ. SP 267. 
457

458

459

460

461

462

463

464

465

466

467

468

469

470

471

472

473

474

475

476

477

478

479

480

481

482

483

484

485

486

487

488

Jackson, P. D., Northmore, K. J., Meldrum, P. I., Gunn, D. A., Hallam, J. R., Wambura, J., Wangusi, B., Ogutu, G., 2002. Non-invasive moisture monitoring within an earth embankment a precursor to failure. Ndt \& E International. 35, 107-115.

Jongmans, D., Garambois, S., 2007. Geophysical investigation of landslides : a review. Bulletin De La Societe Geologique De France. 178, 101-112.

Kim, J. H., Yi, M. J., Song, Y., Seol, S. J., Kim, K. S., 2007. Application of geophysical methods to the safety analysis of an earth dam. Journal of Environmental and Engineering Geophysics. 12, 221-235.

LaBrecque, D.J., Heath, G., Sharpe, R., Versteeg, R., 2004. Autonomous monitoring of fluid movement using 3-D electrical resistivity tomography. Journal of Environmental and Engineering Geophysics, 9(3), 167-176.

Lawson, M. and O'Callaghan, D, 1995. A critical analysis of the role of trees in damage to low rise buildings. Journal of Arboriculture, 21(2), 90-97.

Lebourg, T., Binet, S., Tric, E., Jomard, H., El Bedoui, S., 2005. Geophysical survey to estimate the 3D sliding surface and the 4D evolution of the water pressure on part of a deep seated landslide. Terra Nova. 17, 399-406.

Loke, M.H., and Barker, R.D., 1995. Least-Squares Deconvolution of Apparent Resistivity Pseudosections. Geophysics, 60, 1682-1690.

Loke, $\mathrm{M} \mathrm{H}$ and Barker, $\mathrm{R} \mathrm{D,} \mathrm{1996.} \mathrm{Practical} \mathrm{techniques} \mathrm{for} \mathrm{3D} \mathrm{resistivity} \mathrm{surveys} \mathrm{and} \mathrm{data}$ inversion. Geophysical Prospecting, 44 (3), 499-523.

Niesner, E., 2010. Subsurface resistivity changes and triggering influences detected by continuous geoelectrical monitoring. The Leading Edge, August 2010, 952-955.

Ogilvy, R. D., Meldrum, P. I., Kuras, O., Wilkinson, P. B., Chambers, J. E., Sen, M., Pulido-Bosch, A., Gisbert, J., Jorreto, S., Frances, I. \& Tsourlos, P., 2009. Automated monitoring of coastal aquifers with electrical resistivity tomography. Near Surface Geophysics, 7, 367-375.

Oh, S., 2012. Safety assessment of dams by analysis of the electrical properties of the embankment material. Engineering Geology. 129, 76-90.

Perry, J., Pedley, M., and Reid, M., 2003. Infrastructure embankments - conditional appraisal and remedial treatment. CIRIA, London, U.K., CIRIA Rep. C592.

Ponce, J. W., V.M., 1989. Engineering Hydrology, Principles and Practices. Prentice Hall.

Press, W.H., Teukolsky, S.A., Vetterling, W.T. \& Flannery, B.P., 1992. Numerical Recipes in C: The Art of Scientific Computing, 2nd edn, Cambridge University Press, Cambridge. 
Manning, L. J., Hall, J. W., Kilsby, C. G., Glendinning, S., and Anderson, M. G., 2008. Spatial analysis of the reliability of transport networks subject to rainfall-induced landslides. Hydrological Processes, 22, 3349-3360

Miller, P. E., Mills, J. P., Barr, S. L., Birkinshaw, S. J., Hardy, A. J., Parkin, G., Hall, S. J., 2012. A Remote Sensing Approach for Landslide Hazard Assessment on Engineered Slopes. leee Transactions on Geoscience and Remote Sensing. 50, 1048-1056.

Minsley, B. J., Burton, B. L., Ikard, S., Powers, M. H., 2011. Hydrogeophysical Investigations at Hidden Dam, Raymond, California. Journal of Environmental and Engineering Geophysics. 16, 145-164.

Press, W.H., Teukolsky, S.A., Vetterling, W.T. \& Flannery, B.P., 1992. Numerical Recipes in C: The Art of Scientific Computing, 2nd edn, Cambridge University Press, Cambridge.

Shevnin, V., Mousatov, A., Ryjov, A., Delgado-Rodriquez, O., 2007. Estimation of clay content in soil based on resistivity modelling and laboratory measurements. Geophysical Prospecting. 55, 265-275.

Sjodahl, P., Dahlin, T., Johansson, S., 2009. Embankment dam seepage evaluation from resistivity monitoring data. Near Surface Geophysics. 7, 463-474.

Sjodahl, P., Dahlin, T., Johansson, S., 2010. Using the resistivity method for leakage detection in a blind test at the Rossvatn embankment dam test facility in Norway. Bulletin of Engineering Geology and the Environment. 69, 643-658.

Sjodahl, P., Dahlin, T., Johansson, S., Loke, M. H., 2008. Resistivity monitoring for leakage and internal erosion detection at Hallby embankment dam. Journal of Applied Geophysics. 65, 155164.

Supper, R., Römer, A., Jochum, B., Bieber, G., Jaritz, W., 2008. A complex geo-scientific strategy for landslide hazard mitigation - from airborne mapping to ground monitoring. Advances in Geosciences, 14, 195-200.

Udphuay, S., Gunther, T., Everett, M. E., Warden, R. R., Briaud, J. L., 2011. Three-dimensional resistivity tomography in extreme coastal terrain amidst dense cultural signals: application to cliff stability assessment at the historic D-Day site. Geophysical Journal International. 185, 201220.

Waxman, M. H., Smits, L. J. M., 1968. Electrical conductivities in oil-bearing shaly sands. Society of Petroleum Engineers Journal. 8, 107-122. 
520 Wilkinson, P.B., Chambers, J.E., Meldrum, P.I., Gunn, D.A., Ogilvy, R.D., Kuras, O., 2010a.

521 Predicting the movements of permanently installed electrodes on an active landslide using

522 time-lapse geoelectrical resistivity data only. Geophysical Journal International, 183(2), 543-

523556.

524 Wilkinson, P.B., Meldrum, P.I., Kuras, O., Chambers, J.E., Holyoake, S.J., Ogilvy, R.D., $2010 b$.

525 High-resolution Electrical Resistivity Tomography monitoring of a tracer test in a confined

526 aquifer. J. Appl. Geophys., 70(4), 268-276.

527 Xu, C.Y., Singh, V.P., 2001. Evaluation and generalization of temperature-based methods for

528 calculating evaporation. Hydrological Processes, 15(2), 305-319.

529 
530

531

532

533

534

535

536

537

538

539

540

541

542

543

544

545

546

547

548

549

550

551

552

553

554

555

556

557

558

559

560

561

562

LIST OF FIGURES

Figure 1. Location map showing the Great Central Railway test site at local and national (inset) scale.

Figure 2. Site plan showing an aerial photograph of the study area, and the locations of the 2D and 3D ERT imaging arrays and other monitoring infrastructure, and intrusive sampling locations.

Figure 3. Cross-section through the embankment at $y=12 \mathrm{~m}$, showing topography, borehole $\log (\mathrm{F}$, see Figure 2), depth to bedrock (dashed line), and temperature sensor locations (white circles).

Figure 4. Observed (October 2009-July 2010) \& modelled ground temperatures, Great Central Railway test site.

Figure 5. Variation in resistivity with gravimetric moisture content in laboratory samples of Westbury Mudstone Formation embankment material taken from the Great Central Railway test site. The best-fit Waxman-Smits model is shown as the solid line.

Figure 6. Weekly rainfall, weekly effective rainfall (Blaney - Criddle method), and weekly average air temperature for the (a) 2D and (b) 3D ERT monitoring periods.

Figure 7. Temperature corrected 2D ERT model sections (left) and log resistivity ratio plots (right) showing changes in resistivity relative to the July 2006 baseline (top left).

Figure 8. ERT derived gravimetric moisture content (left) and ratio (right) plots calculated using the resistivity moisture content relationships determined from laboratory testing (Figure 5).

Figure 9. Temperature corrected 3D ERT models for (a) $16^{\text {th }}$ February 2011 , (b) $30^{\text {th }}$ October 2011 , and (c) $29^{\text {th }}$ January 2012, and the corresponding 3D gravimetric moisture content models for (d) $16^{\text {th }}$ February 2011, (e) $30^{\text {th }}$ October 2011, and (f) $29^{\text {th }}$ January 2012, calculated using the resistivity moisture content relationships determined from laboratory testing (Figure $5)$.

Figure 10. Time-series plots showing mean gravimetric moisture content variation with time at three different spatial scales: (a) embankments flanks and crest (coarse); (b) east and west toes (intermediate); (c) two discrete volumes in the toe region of the western flank (finescale). 


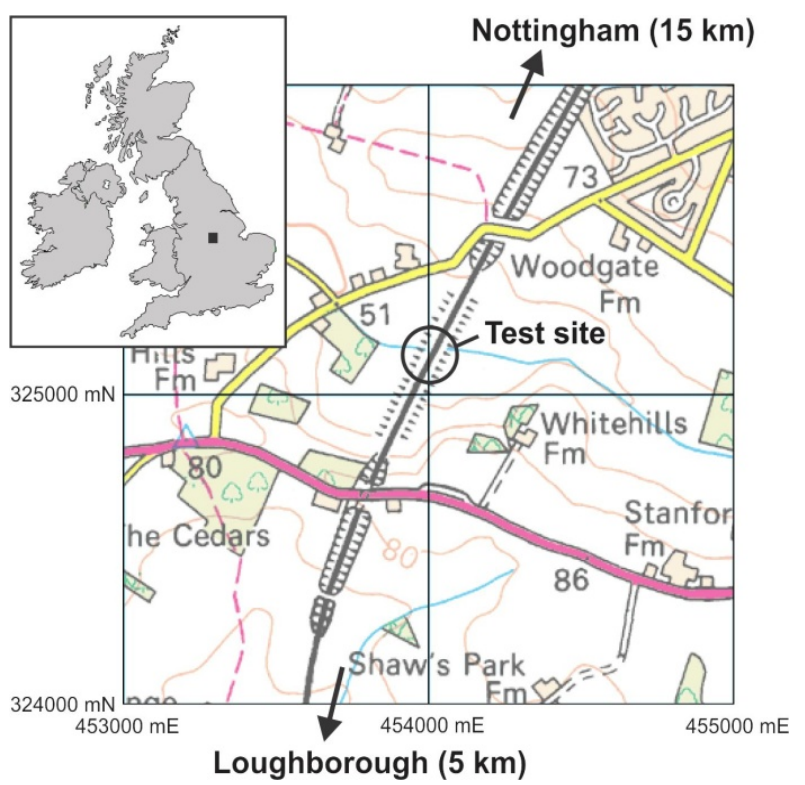

577 Figure 1. Location map showing the Great Central Railway test site at local and national (inset) 578 scale. 


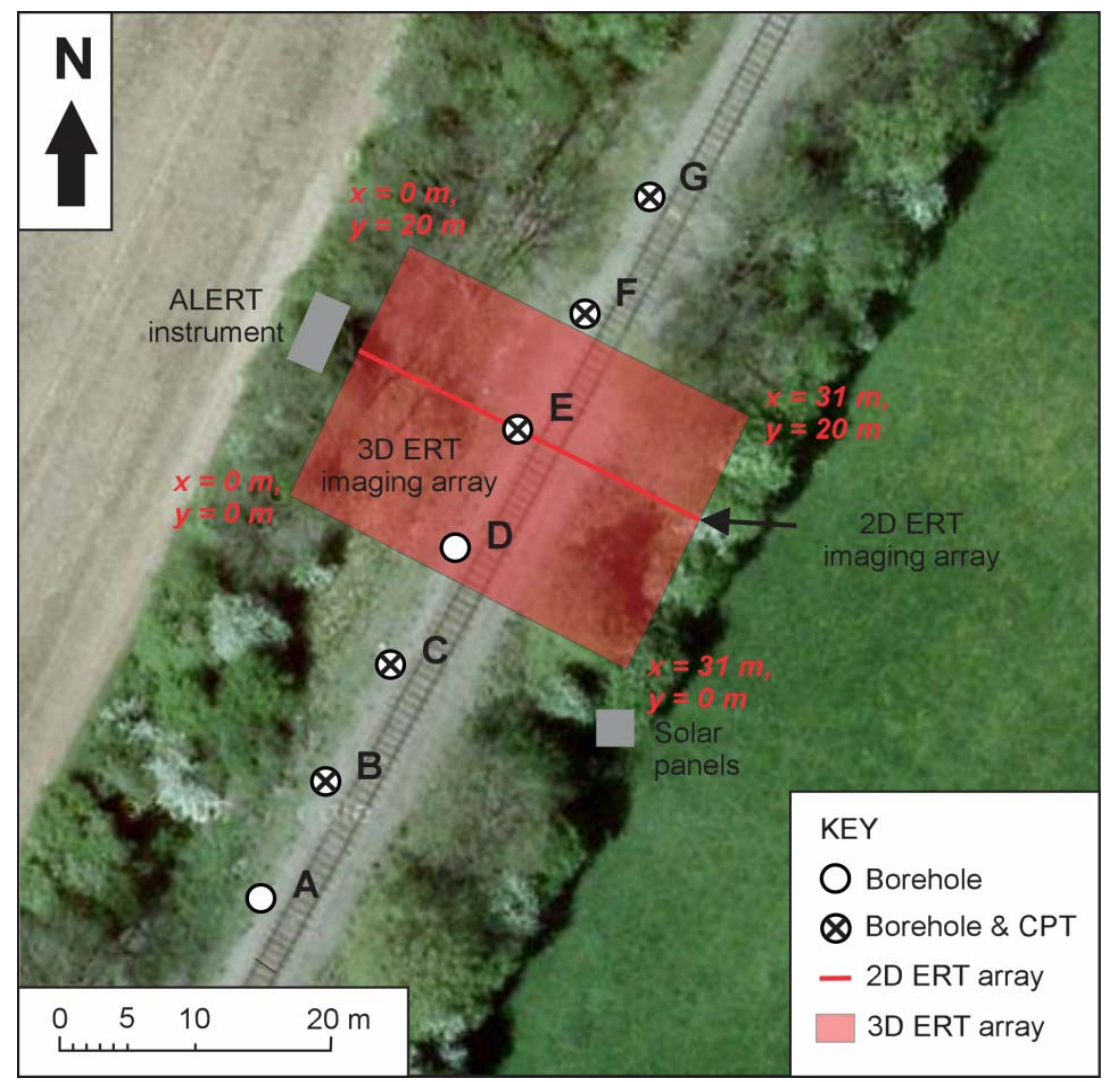

593 Figure 2. Site plan showing an aerial photograph of the study area, and the locations of the 2D 594 and 3D ERT imaging arrays and other monitoring infrastructure, and intrusive sampling 595 locations. 
600

601

602

603

604

605

606

607

608

609

610

611

612

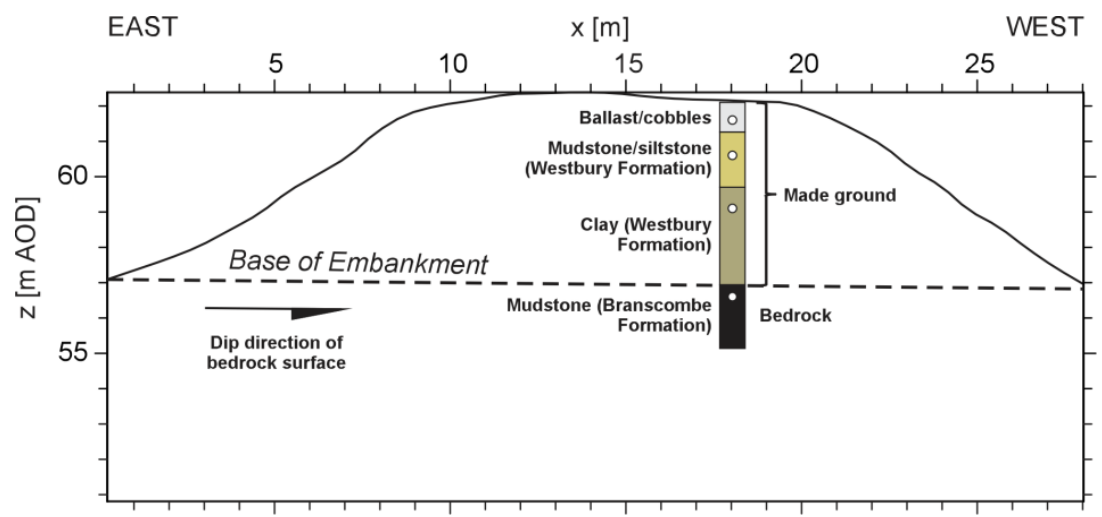

613 Figure 3. Cross-section through the embankment at $y=12 \mathrm{~m}$, showing topography, borehole

$614 \log (F$, see Figure 2), depth to bedrock (dashed line), and temperature sensor locations (white 615 circles).

616

617

618

619

620 

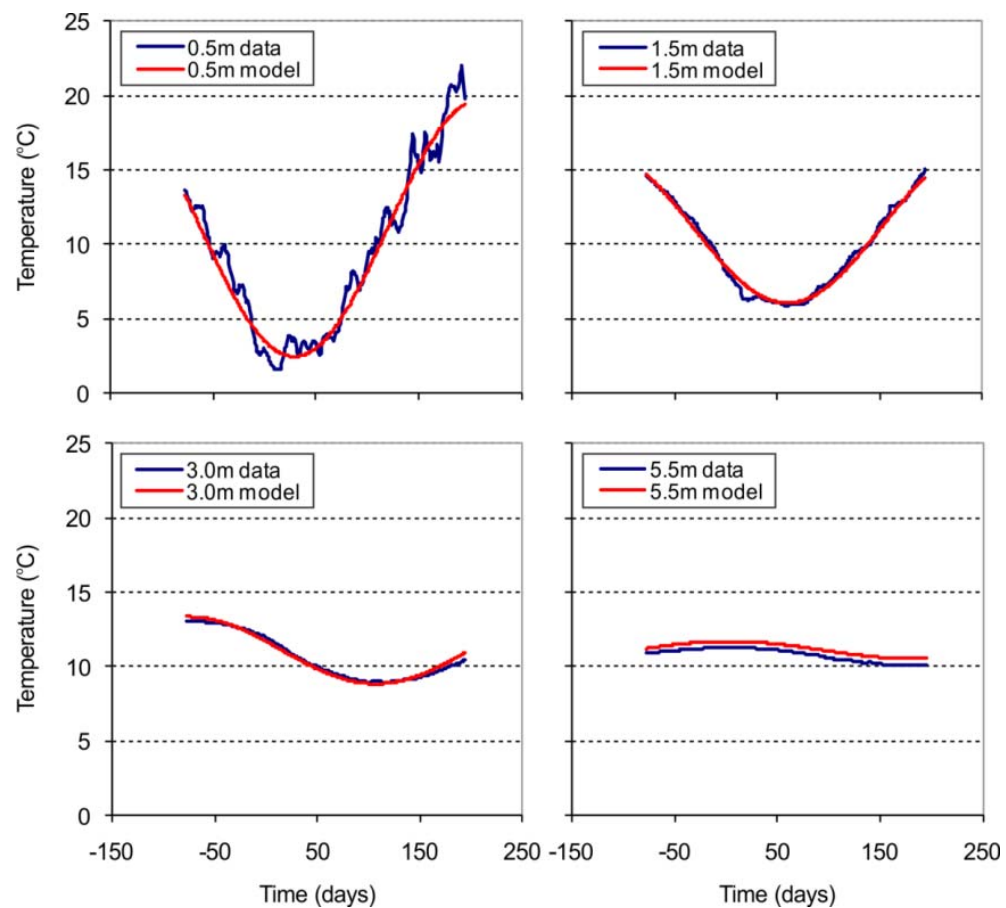

629 Figure 4. Observed (October 2009-July 2010) \& modelled ground temperatures, Great Central 630 Railway test site.

631

632

633 
634

635

636

637

638

639

640

641

642

643

644

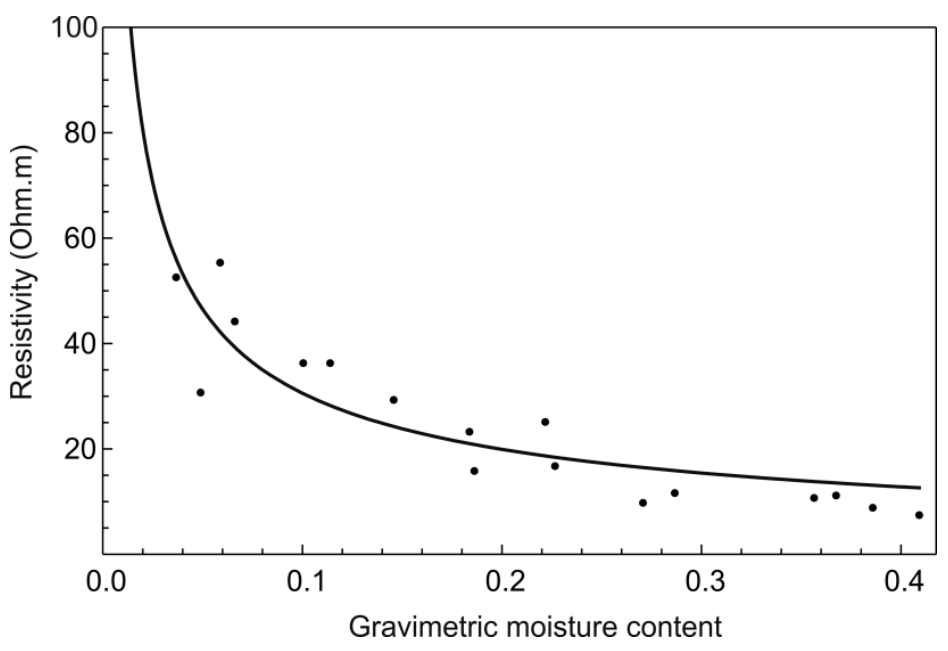

645

646 Figure 5. Variation in resistivity with gravimetric moisture content in laboratory samples of 647 Westbury Mudstone Formation embankment material taken from the Great Central Railway 648 test site. The best-fit Waxman-Smits model is shown as the solid line.

649

650 


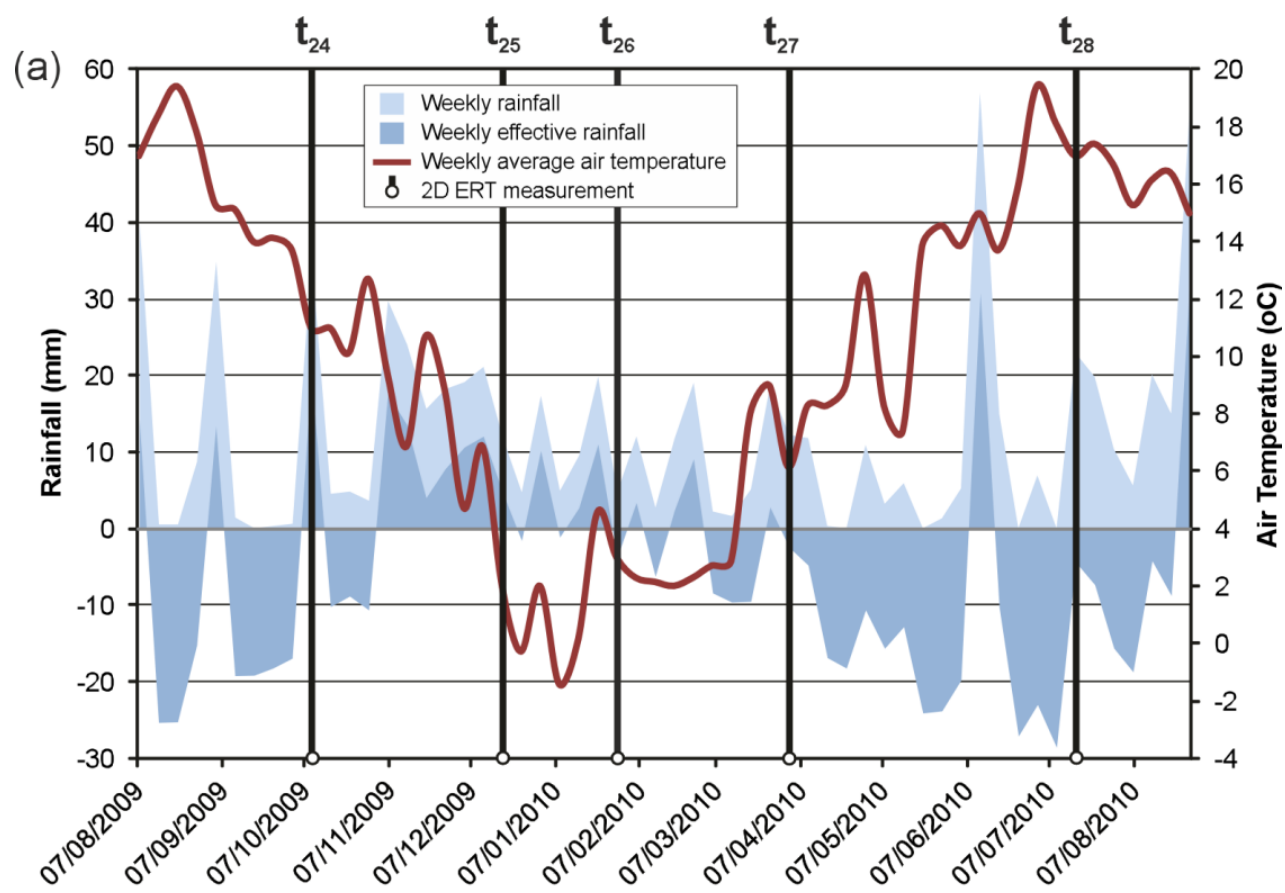

(b)

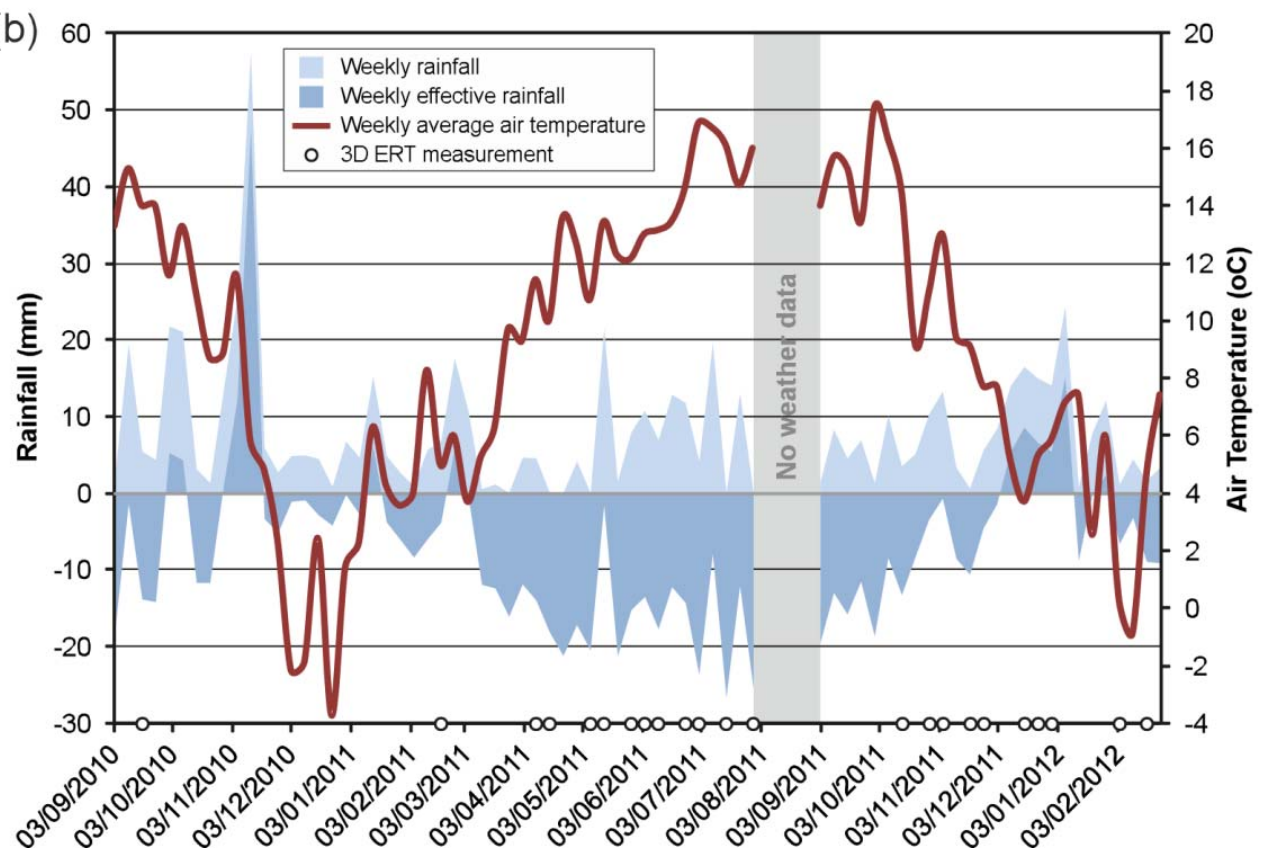

Figure 6. Weekly rainfall, weekly effective rainfall (Blaney - Criddle method), and weekly average air temperature for the (a) 2D and (b) 3D ERT monitoring periods. 



664 Figure 7. Temperature corrected 2D ERT model sections (left) and log resistivity ratio plots 665 (right) showing changes in resistivity relative to the July 2006 baseline (top left). 
667
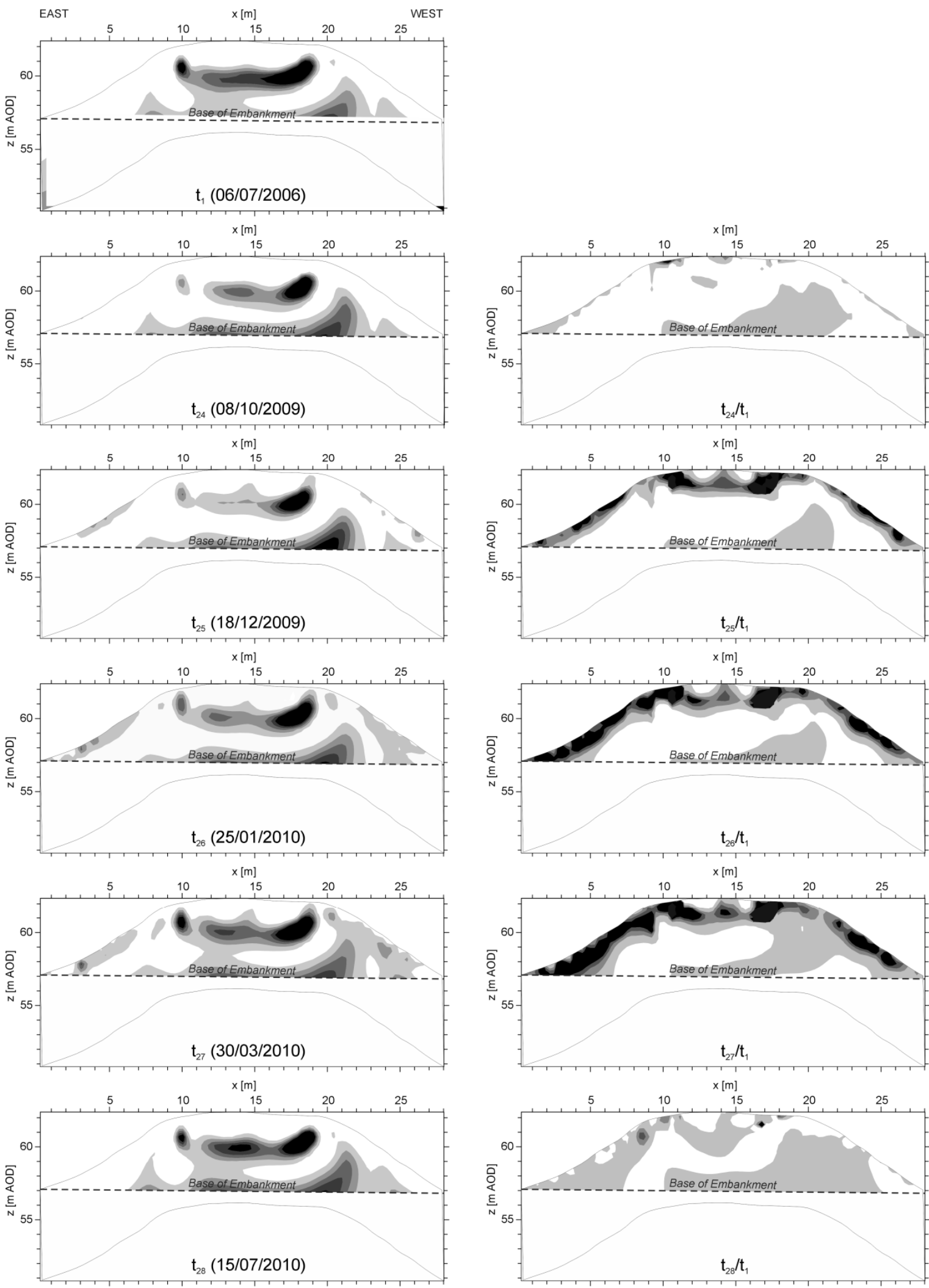

Gravimetric moisture content (GMC)

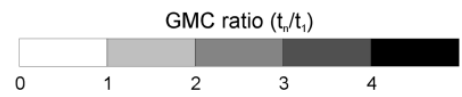

669 Figure 8. ERT derived gravimetric moisture content (left) and ratio (right) plots calculated using the resistivity moisture content relationships determined from laboratory testing (Figure 5). 
(a)
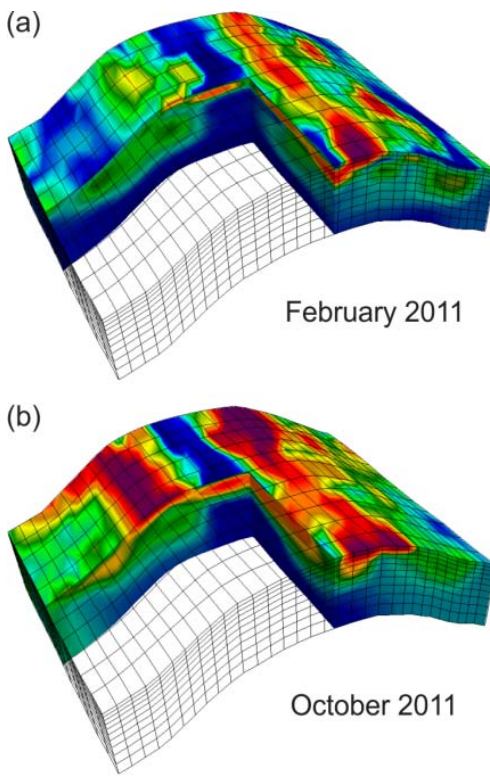

(c)

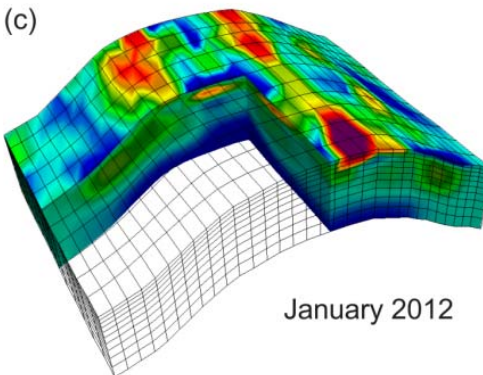

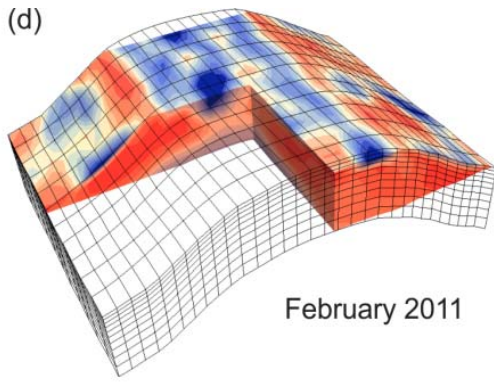

(e)

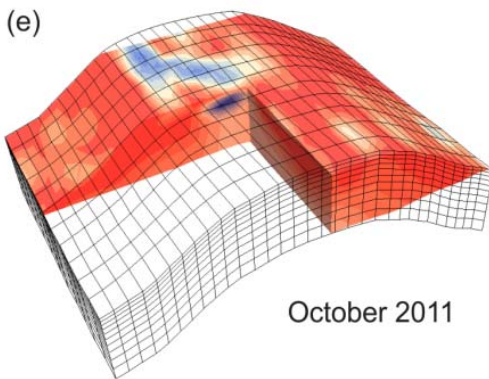

(f)

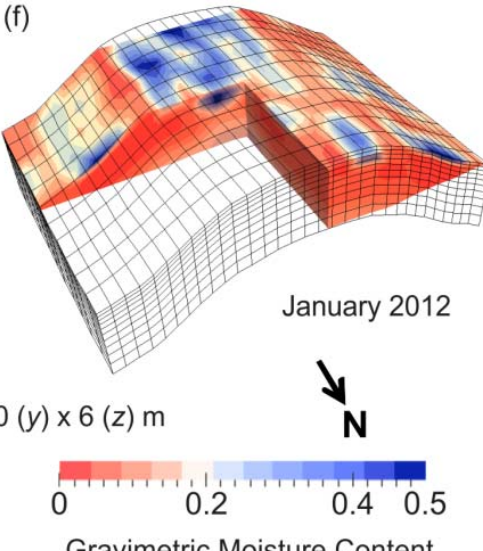

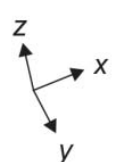

Dimensions $30(x) \times 20(y) \times 6(z) \mathrm{m}$

678 Figure 9. Temperature corrected 3D ERT models for (a) $16^{\text {th }}$ February 2011, (b) 30 ${ }^{\text {th }}$ October 6792011 , and (c) 29 ${ }^{\text {th }}$ January 2012, and the corresponding 3D gravimetric moisture content 680 models for (d) $16^{\text {th }}$ February 2011, (e) $30^{\text {th }}$ October 2011, and (f) $29^{\text {th }}$ January 2012, calculated 681 using the resistivity moisture content relationships determined from laboratory testing (Figure 682 5). 
a)

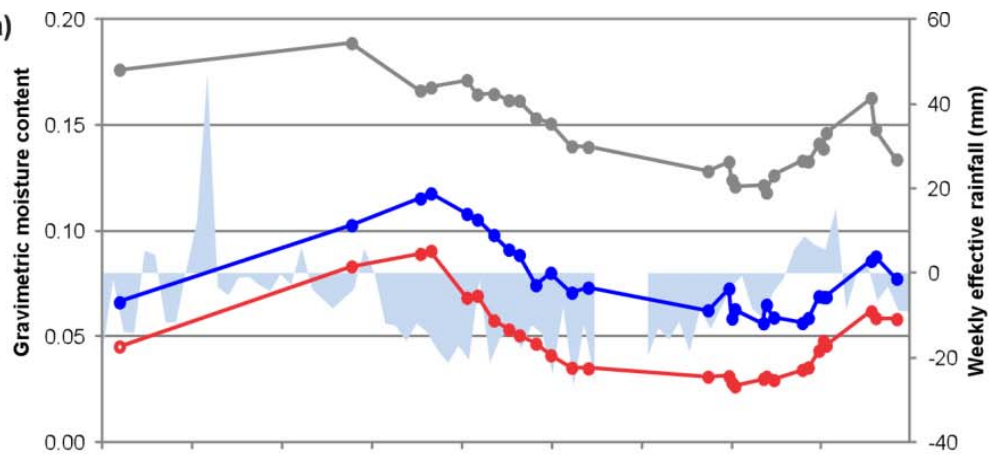

b)

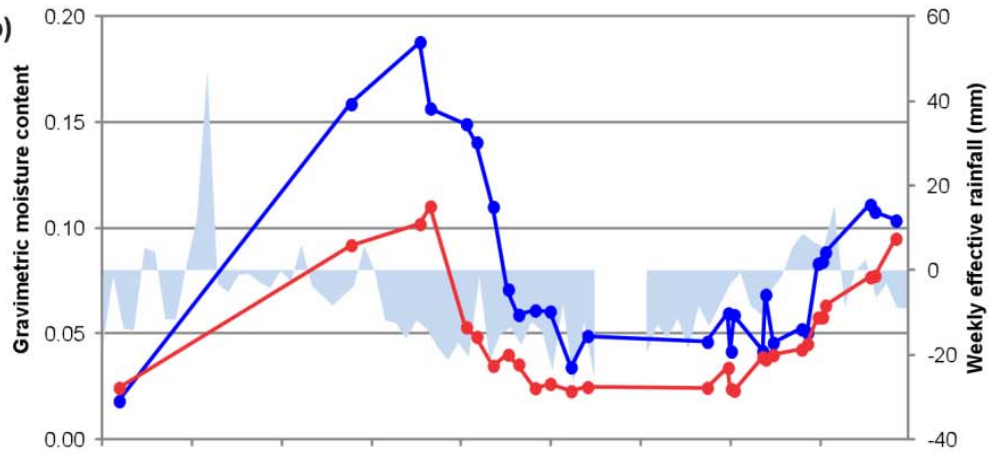

c)
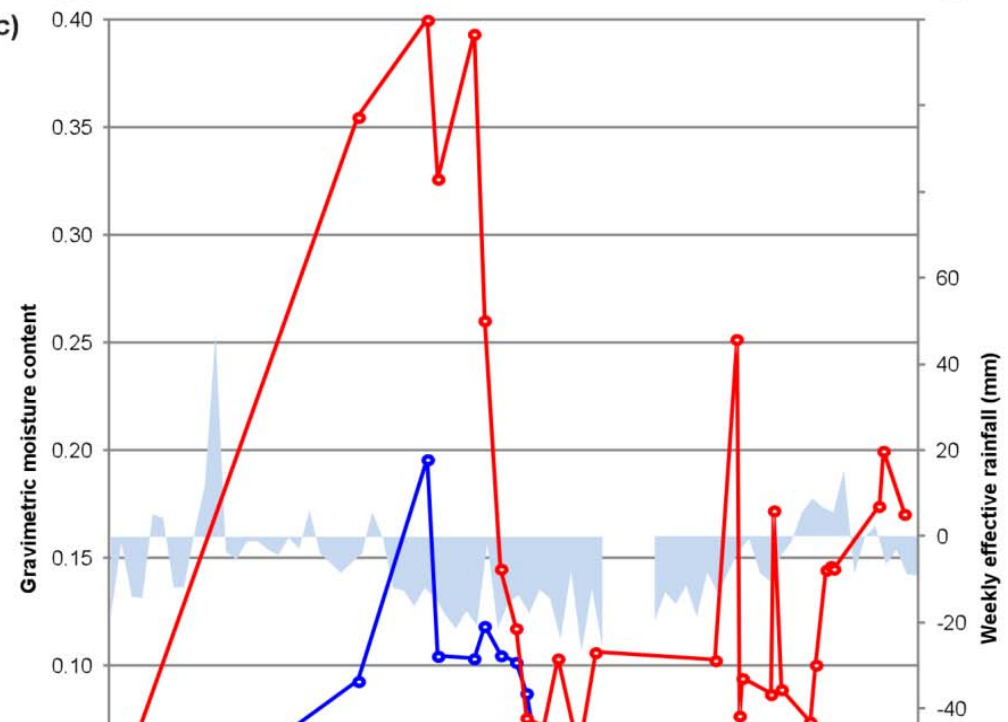
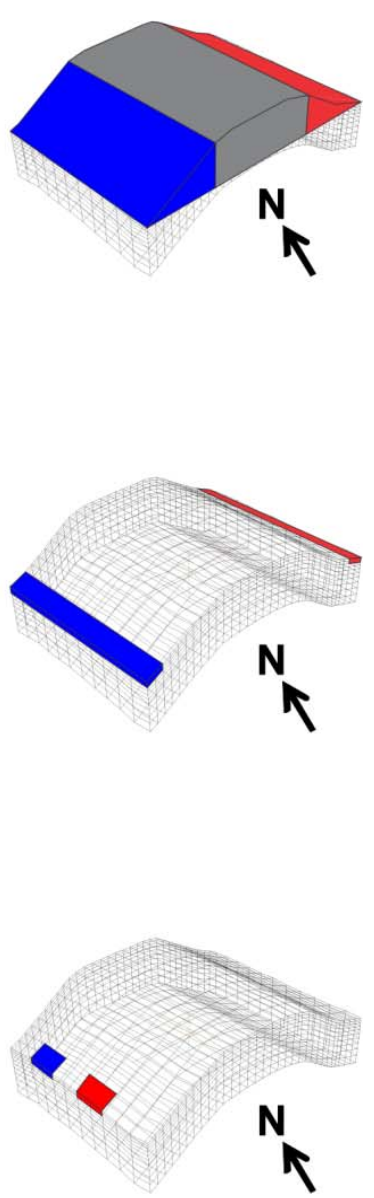